\title{
EXPERIMENTAL INVESTIGATION ON FLEXURAL BEHAVIOUR OF FLOWABLE RC BEAM USING WELDED WIRE MESH AS SHEAR REINFORCEMENT
}

\author{
C.P. Pearlin \\ Assistant Professor, Department of Civil Engineering, \\ SMK Fomra Institute of Technology, Kelambakkam, Chennai, Tamil Nadu, India

\section{S. Kesavraman} \\ Assistant Professor, Department of Civil Engineering, \\ SMK Fomra Institute of Technology, Kelambakkam, Chennai, Tamil Nadu, India

\section{Velmurugan} \\ Assistant Professor, Department of Civil Engineering, \\ SMK Fomra Institute of Technology, Kelambakkam, Chennai, Tamil Nadu, India
}

\begin{abstract}
An alternative reinforcement system, Welded wire mesh is proposed to perform the function of transverse steel in Reinforced Concrete Beams. Welded mesh reinforcement eliminates some of the detailing problems inherent in traditional rebar in the Reinforced Concrete Construction resulting in easier and faster construction, and better economy and quality control. Since the mesh size is very small and to ensure strength and homogeneity, self compacting concrete is to be used. Selfcompacting concrete consists of the same components as conventionally vibrated concrete with the addition of chemical and mineral admixtures in different proportions. In present study SCC is developed by replacing cement with silica fume of $4 \%$ and $6 \%$. This project is to examine the flexural behavior and crack pattern of $R C$ beam. Totally five variations of beam were caste and number of mesh layers with percentage of silica fume are varied in each specimen. It is obtained that the beam with continuous welded wire mesh and longitudinal bar given the maximum load carrying capacity and it is found that there is improvement in strength characteristics while using mesh layer and silica fume when compared with control specimen.
\end{abstract}

Keywords: Welded Wire Mesh, Self Compacting Concrete (SCC), RC beams, Silica Fume, Flexural behavior, durability 
Cite this Article: C.P. Pearlin, S. Kesavraman and M. Velmurugan, Experimental Investigation on Flexural Behaviour of Flowable RC Beam Using Welded Wire Mesh as Shear Reinforcement, International Journal of Civil Engineering and Technology, 11(6), 2020, pp. 8-17. https://iaeme.com/Home/issue/IJCIET?Volume=11\&Issue $=6$

\section{INTRODUCTION}

The experimental study carried out under this paper is the flexural behavior of self compacting RC beam using welded wire mesh as shear reinforcement. The development of reinforced concrete structures was been largely employed under different methods and various situation based upon the conditions in engineering practice. The uses of welded wire mesh (varying from one and two layer respectively) as the shear reinforcement in the flexural and shear behavior. The welded wire mesh has a better characteristic strength and excellent bonding capacity. It is formed from stainless steel that has extraordinary strength and reliability. Welded mesh has been widely used in buildings that Weld mesh can be a good substitute for the conventional reinforcement and yielded excellent results both in strength and ductility. Because of its economy, ease of availability and faster of construction as well as better quality control, welded Wire Mesh as widely used. Inadequate shear reinforcement causes shear failure. If the shear stress rides over the shear carrying capacity, the structures are possible to fail in brittle manner. To overcome all above problems, Welded wire mesh is used as shear reinforcement. If we use closely spacing interlocks, the reinforced concrete member provides good ductility and bearing capacity. Self-compacting concrete is cast so that no additional inner or outer vibration is necessary for the compaction. This study is done using five beam specimens. Out of them four specimens are wound with welded wire mesh and the number of mesh layers with variation shown in proportion of silica fume is done in each case, while the other specimen is with conventional reinforcement used as control specimen. The parameters which are investigated in this study, includes the ultimate load carrying capacity, maximum deflection, flexural strength, crack patterns, ductility and durability. Testes of reinforced concrete beams indicates that there is improvement in strength characteristics and load carrying capacity in beam with two layers WWM and low percentage of silica fume when compared with control specimen.

\section{EXPERIMENTAL PROGRAM}

The experimental investigation conducted as discussed below. Test for all materials were conducted in laboratory as per relevant Indian standard codes. Preliminary test were conducted on fine aggregate, coarse aggregate and cement to check their suitability for concrete preparation. After the basic test were conducted the compressive strength of the mix design of self compacting concrete (M 35 grade) was verified. After testing the compressive strength, the fresh concrete test was performed for SCC and mix was found to be satisfying. The study aims to investigate the strength related properties of M 35 grade of concrete. The correct mix proportions of ingredients for M 35 grade of concrete has been determined by mix design as per guidelines given for self compacting concrete design. Totally three variations of cubes and cylinders were cast for M 35 grade of concrete in this study. Five variations of beams were with varying the mesh layers and also with the variations in proportion of silica fume. The parameters to be investigated in this study included the spacing and grid configuration of welded wire mesh and the shear reinforcement. Six beams of size $1000 \mathrm{~mm} x$ $230 \mathrm{~mm} \times 230 \mathrm{~mm}$ were cast and cured. 


\subsection{Description of Specimen}

The current experimental program includes five variations of beam specimens, the description of specimens are designated as follows,

SP 1: The specimen is fully stirrups with conventional shear reinforcement, which is said to be control specimen.

SP 2: The specimen is with $4 \%$ of silica fume and with the variation of one layer, welded wire mesh.

SP 3: The specimen is with $6 \%$ of silica fume and with the variation of one layer, welded wire mesh.

SP 4: The specimen is with $4 \%$ of silica fume and with the variation of two layers, welded wire mesh.

SP 5: The specimen is with $6 \%$ of silica fume and with the variation of two layers, welded wire mesh.

\subsection{Material Properties}

In this study commercially available Ordinary Portland Cement (OPC) of grade 53, is used according to IS: $1489-1991$ with specific gravity 3.15 conforming to IS: 12269-2013.

Fine aggregate is locally available river sand of size below $4.75 \mathrm{~mm}$ with specific gravity 2.78 conforming to zone II of IS 383-1970 is used as fine aggregate. The physical properties as per IS 2368 (part III) were also found using laboratory experiments.

Coarse aggregate is used in this study consist of maximum size $12 \mathrm{~mm}$ and $6 \mathrm{~mm}$. The physical properties as per IS 383-1970 were also found using laboratory experiments. The specific gravity is 2.66 .

HYSD bars with diameter $12 \mathrm{~mm}$ and $10 \mathrm{~mm}$ were used as longitudinal tension and compression reinforcement and for lateral ties $8 \mathrm{~mm}$ diameter were used respectively. The welded wire mesh with spacing $12.5 \mathrm{~mm}$ and diameter $2 \mathrm{~mm}$ were used.

Silica fume of specific gravity 2.1 as cement replacement and super plasticizer (Glenium B233) were used with dosage of $0.8 \%$ of total weight of the cement content, dosage found using marsh cone test.

Table 1 Details of beam specimens tested

\begin{tabular}{|c|c|c|c|c|c|c|}
\hline $\begin{array}{c}\text { Specimen } \\
\text { Name }\end{array}$ & $\begin{array}{c}\text { Cross section } \\
\text { details (mm) }\end{array}$ & $\begin{array}{c}\text { Length } \\
(\mathbf{m m})\end{array}$ & $\begin{array}{c}\text { Reinforcement } \\
\text { in tension }\end{array}$ & $\begin{array}{c}\text { Reinforcement } \\
\text { in compression }\end{array}$ & Stirrups & $\begin{array}{c}\text { No. of } \\
\text { WWM } \\
\text { layer }\end{array}$ \\
\hline SP 1 & $230 \times 230$ & 1000 & $2 \# 12 \mathrm{~mm}$ & $2 \# 10 \mathrm{~mm}$ & $6 \# 8 \mathrm{~mm}$ & nil \\
\hline SP 2 & $230 \times 230$ & 1000 & $2 \# 12 \mathrm{~mm}$ & $2 \# 10 \mathrm{~mm}$ & $2 \# 8 \mathrm{~mm}$ & 1 \\
\hline SP 3 & $230 \times 230$ & 1000 & $2 \# 12 \mathrm{~mm}$ & $2 \# 10 \mathrm{~mm}$ & $2 \# 8 \mathrm{~mm}$ & 1 \\
\hline SP 4 & $230 \times 230$ & 1000 & $2 \# 12 \mathrm{~mm}$ & $2 \# 10 \mathrm{~mm}$ & $2 \# 8 \mathrm{~mm}$ & 2 \\
\hline SP 5 & $230 \times 230$ & 1000 & $2 \# 12 \mathrm{~mm}$ & $2 \# 10 \mathrm{~mm}$ & $2 \# 8 \mathrm{~mm}$ & 2 \\
\hline
\end{tabular}

\subsection{Preparation of Specimen}

The beam specimens are prepared according to the following procedure.

\subsubsection{Reinforcement}

Two bars of $12 \mathrm{~mm}$ diameter as tension reinforcement and $10 \mathrm{~mm}$ as compression reinforcement were used as longitudinal reinforcement. Each of the beam specimens has distinguished lateral reinforcement with mesh layers as given in table 1 and shown in below 
figure. The welded wire mesh was connected to the beam specimen with the help of winding wires. The cover of the specimen is maintained as $25 \mathrm{~mm}$.

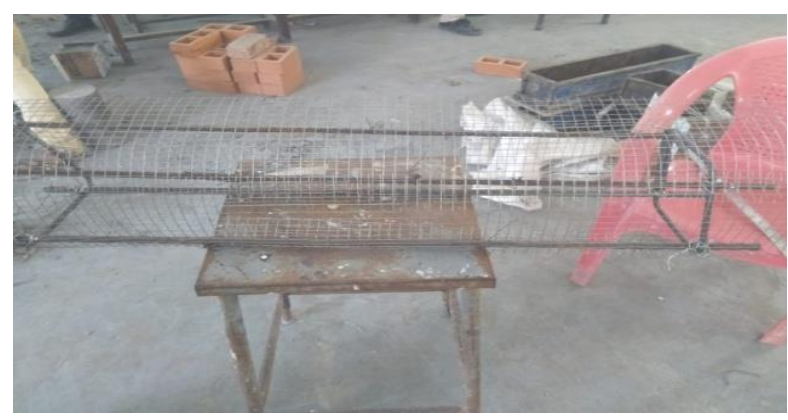

Figure 1 Reinforcement with one layer WWM

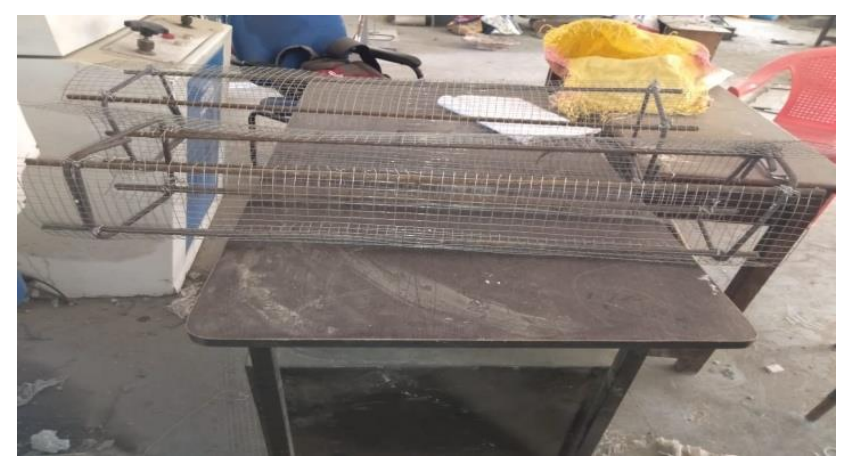

Figure 2 Reinforcement with two layer WWM

\subsubsection{Mixing and casting of beam specimen}

The mixing of the specimen was done after the fresh concrete test for SCC. The mix design for self compacting concrete was done by following respective standards. The cube compressive strength obtained for mix design is given as follows.

Table 2 SCC concrete mix design ratio

\begin{tabular}{|c|c|c|c|c|}
\hline Unit & Cement & FA & CA & Water \\
\hline Ratio & 1 & 2.142 & 1.683 & 0.45 \\
\hline
\end{tabular}

Table 3 Quantity of materials for one beam

\begin{tabular}{|l|l|l|}
\hline \multirow{3}{*}{ Cement } & Total weight & $28.944 \mathrm{Kg} / \mathrm{m}^{3}$ \\
\cline { 2 - 3 } & When $4 \%$ of cement replaced & $27.786 \mathrm{Kg} / \mathrm{m}^{3}$ \\
\cline { 2 - 3 } & When 6\% of cement replaced & $27.207 \mathrm{Kg} / \mathrm{m}^{3}$ \\
\hline Silica fume & When $4 \%$ of total cement & $1.158 \mathrm{Kg} / \mathrm{m}^{3}$ \\
\cline { 2 - 3 } & When $6 \%$ of total cement & $1.737 \mathrm{Kg} / \mathrm{m}^{3}$ \\
\hline FA & Total weight & $61.998 \mathrm{Kg} / \mathrm{m}^{3}$ \\
\hline CA & Total weight & $48.713 \mathrm{Kg} / \mathrm{m}^{3}$ \\
\hline $12 \mathrm{~mm}$ aggregate & $60 \%$ of total aggregate & $29.228 \mathrm{Kg} / \mathrm{m}^{3}$ \\
\hline 6mm aggregate & $60 \%$ of total aggregate & $19.485 \mathrm{Kg} / \mathrm{m}^{3}$ \\
\hline water & Total weight & $12.795 \mathrm{lit}$ \\
\hline SP & Total weight & $0.23 \mathrm{lit}$ \\
\hline
\end{tabular}


All the obtained values are within the permissible limits. The mixing of the concrete was done in an electronic drum mixture machine and poured with self compacting mixture machine manually. The specimens were un-mould after 24 hours and cured in water for 28 days. After curing they were kept for drying and coated with lime for visibility of cracks during testing.

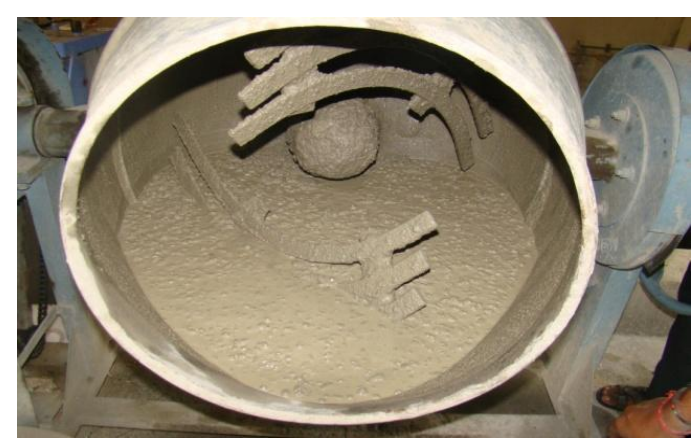

Figure 3 SCC mix in the electronic drum mixture

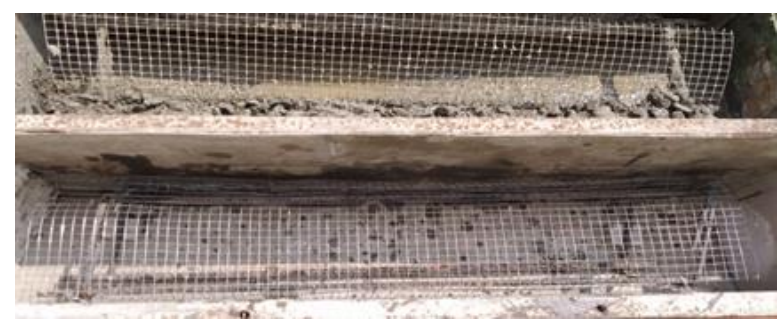

Figure 4 Specimen during casting

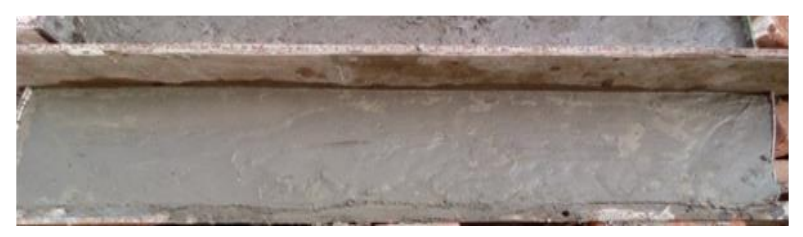

Figure 5 Specimen after casting

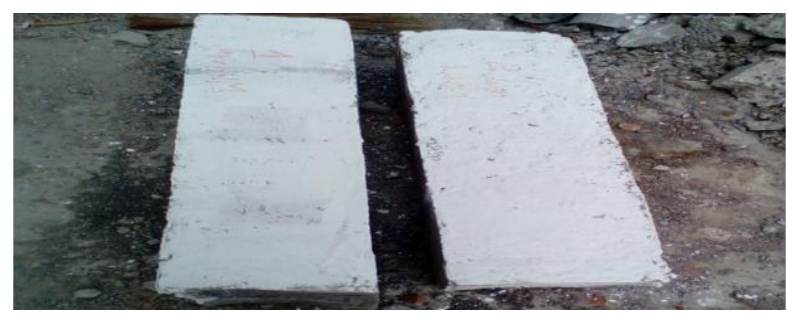

Figure 6 Specimen ready for testing

\subsubsection{Instrumentation and test setup}

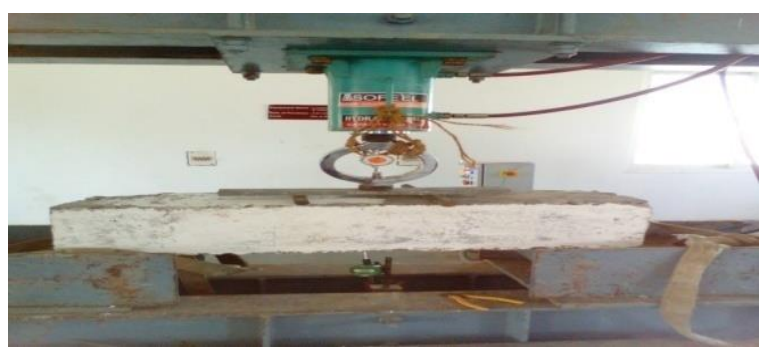

Figure 7 Test setup of the specimen 
The instrumentation and test setup are shown in figure 7. Test was conducted using hydraulic loading machine mounted on a testing frame capacity of $500 \mathrm{KN}$. All the specimens were kept at a span length of $1000 \mathrm{~mm}(\mathrm{~L})$ and were subjected with two- point loading. The deflection at the middle, $L / 3$ and $2 L / 3$ of the span were measured using dial gauges.

\section{EXPERIMENTAL RESULTS AND DISCUSSION}

The test results of all the corresponding test of the specimens are listed below,

Table 4 Test results for fresh SCC

\begin{tabular}{|c|l|c|c|}
\hline S.NO & \multicolumn{1}{|c|}{ Name of the test } & Test values & Remarks \\
\hline 1. & Slump flow diameter & $710 \mathrm{~mm}$ & Acceptable \\
\hline 2. & $\mathrm{~T}_{500}$ & $4.6 \mathrm{sec}$ & Acceptable \\
\hline 3. & L box test $\left(\mathrm{H}_{1} / \mathrm{H}_{2}\right)$ & $0.85 \mathrm{sec}$ & Acceptable \\
\hline
\end{tabular}

Table 5 Test results for harden SCC

\begin{tabular}{|c|c|c|c|c|c|}
\hline S.NO & \multirow{2}{*}{ Type } & \multicolumn{2}{|c|}{ Compressive Strength $\left(\mathbf{N} / \mathbf{m m}^{2}\right)$} & \multicolumn{2}{c|}{ Tensile Strength $\mathbf{( N / \mathbf { m m } ^ { 2 } )}$} \\
\cline { 3 - 6 } & & $\mathbf{7 ~ d a y s}$ & $\mathbf{2 8}$ days & $\mathbf{7 ~ d a y s}$ & $\mathbf{2 8 ~ d a y s ~}$ \\
\hline 1. & Type 1 & 24.71 & 36.21 & 3.45 & 4.16 \\
\hline 2. & Type 2 & 31.84 & 42.34 & 3.57 & 4.88 \\
\hline 3. & Type 3 & 31.35 & 39.85 & 3.48 & 4.74 \\
\hline
\end{tabular}

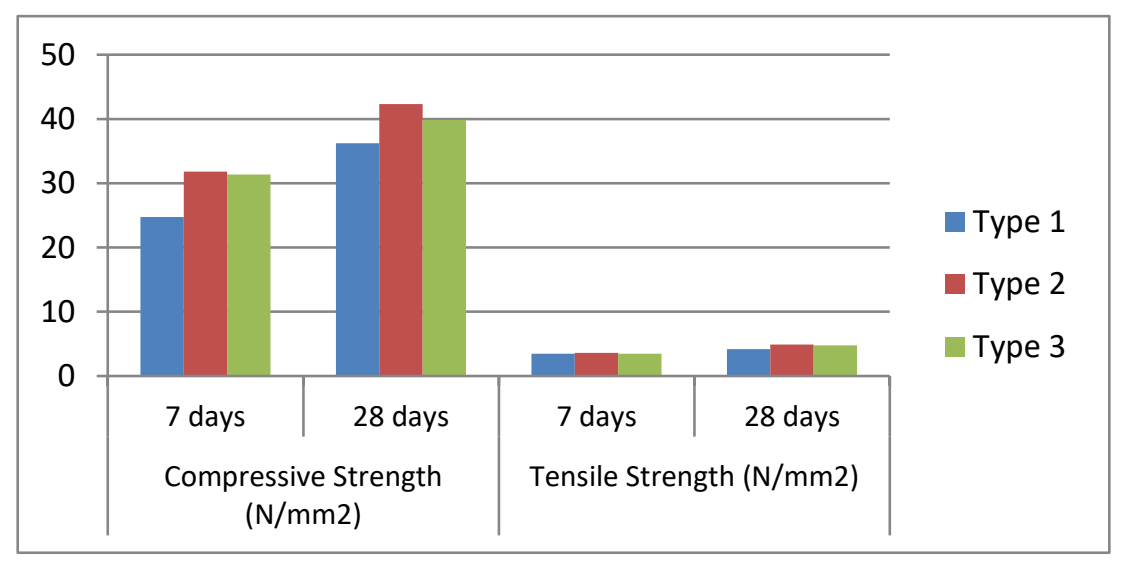

Figure 8 Test results for harden SCC

\subsection{Ultimate Load}

The experimental results suggest that the ultimate load carrying capacity of beam specimen is increased only marginally for the SP 2 and SP 3 with the increase of one layer of welded wire mesh. But with increasing the mesh spacing by increasing the mesh layers in SP 4 and SP 5, the ultimate load carrying capacity is found to be increased. It is found that from SP 3 with single mesh layer and high percentage of silica fume there is no increment in value of strength when the spacing of the stirrups is increased. Future study using, less percentage of silica fume are recommended. When double layer of welded wire mesh with $4 \%$ of silica fume are used in SP 4, the strength increased when compared with the control specimen and the specimen with $6 \%$ of silica fume in SP 5, the strength value gets increased but less than the SP 4 . Therefore the beam with double layer of welded wire mesh and wit $4 \%$ of silica fume 
can because as an alternative to control specimen. The alternatives proposed for SP 1 are SP 4 and SP5.

\subsection{Maximum Deflection}

The maximum deflection values of specimen increased in SP 2 with addition of one layer of WWM. The deflection value decreases for SP 4 when compared with the control specimen. Also there is no remarkable increase in the maximum deflection value by providing double layer of welded wire mesh. Even though, with lesser number of stirrups and double layer of WWM, we are able to achieve higher deflection value.

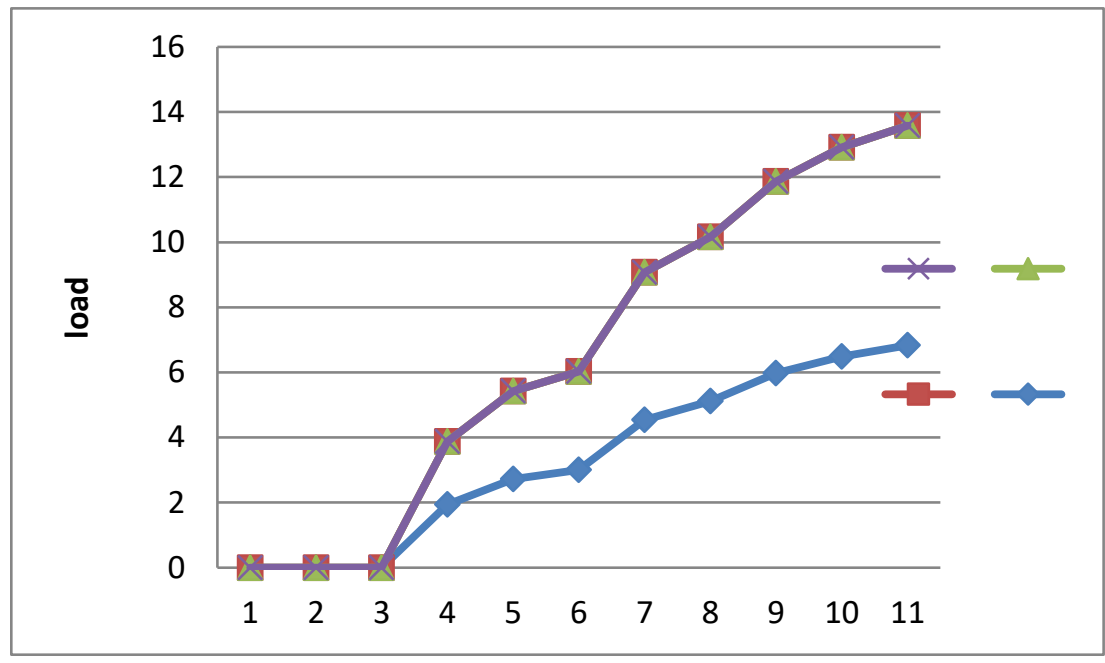

Figure 9 Load Vs Deflection curve for SP 1

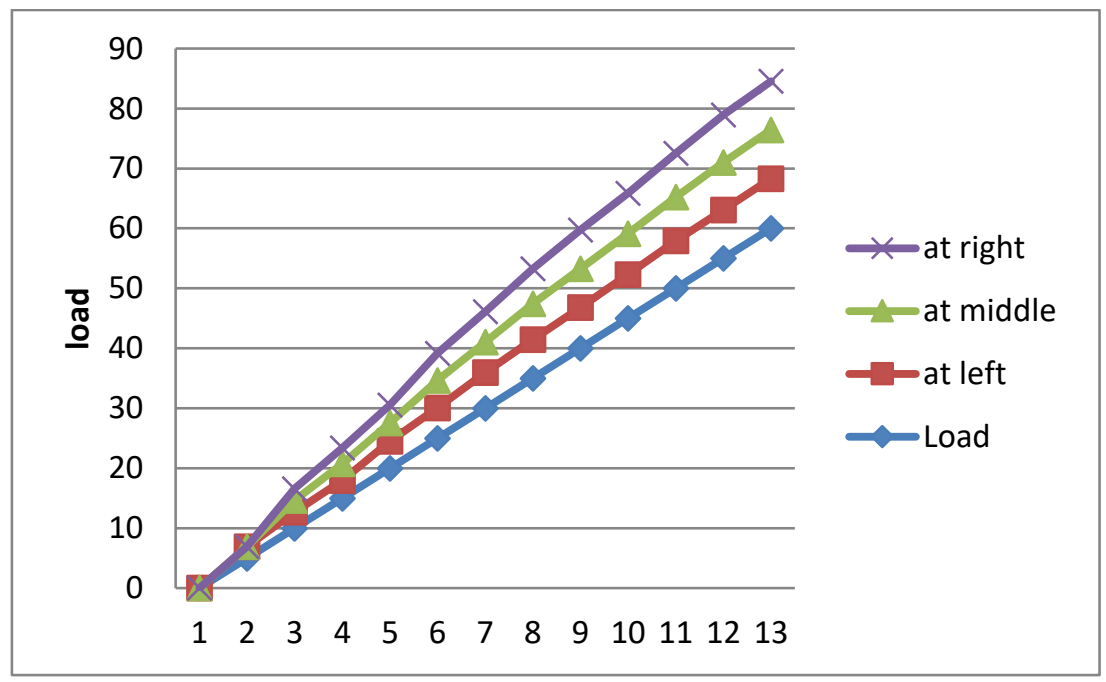

Figure 10 Load Vs Deflection curve for SP 2 
Experimental Investigation on Flexural Behaviour of Flowable RC Beam Using Welded Wire Mesh as Shear Reinforcement

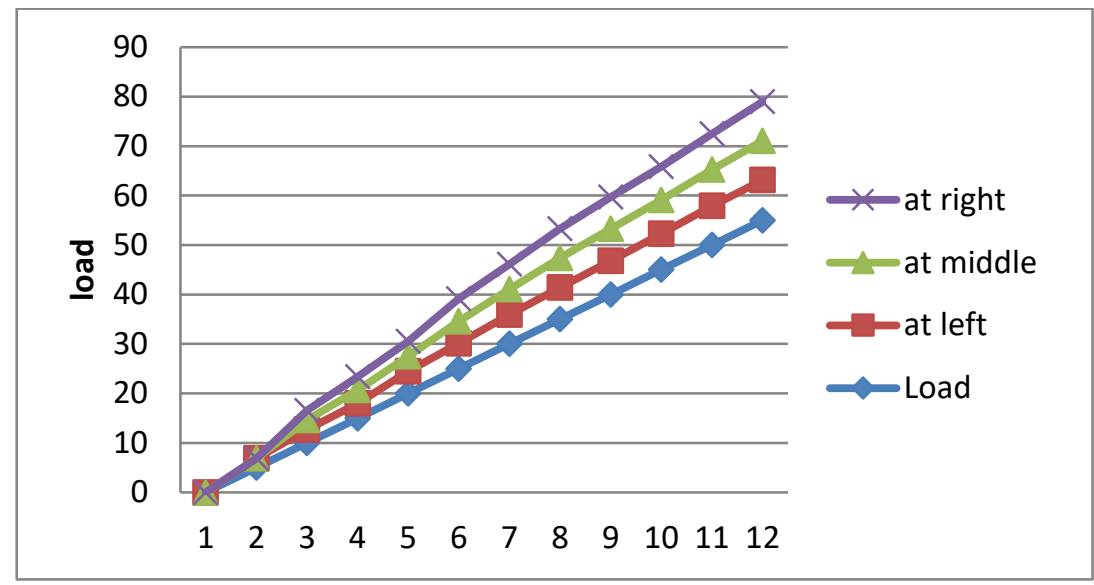

Figure 11 Load Vs Deflection curve for SP 3

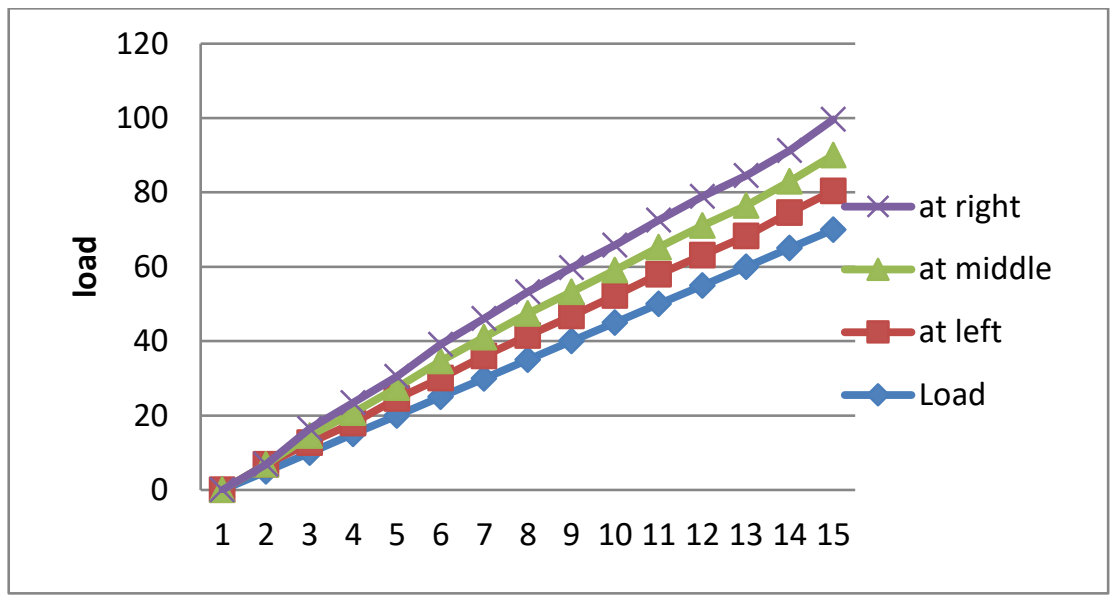

Figure 12 Load Vs Deflection curve for SP 4

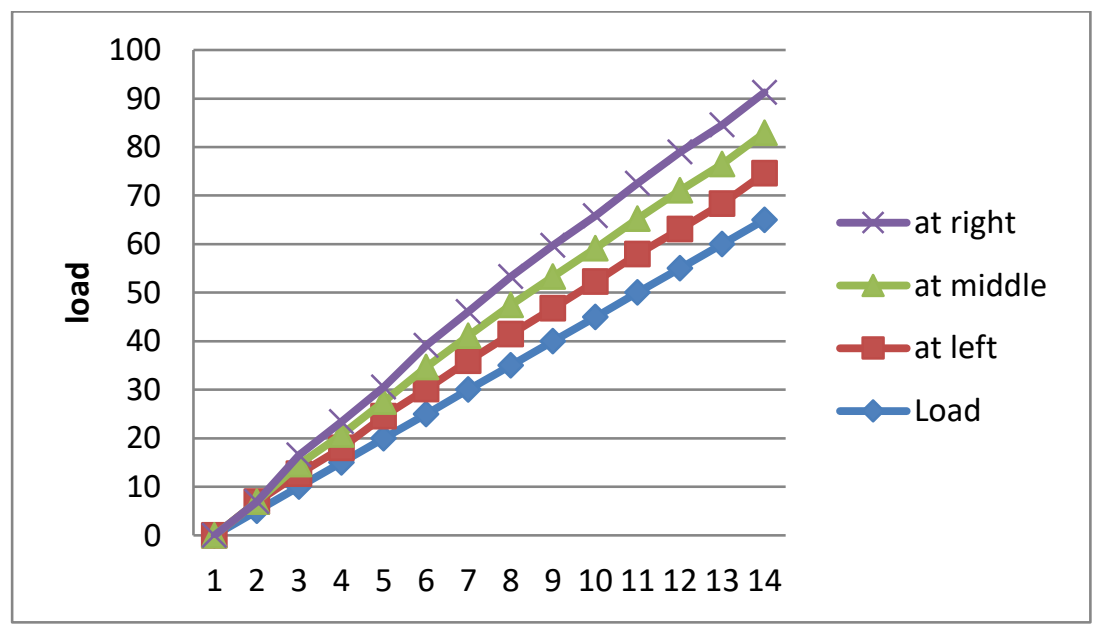

Figure 13 Load Vs Deflection curve for SP 5

significantly. Also by reducing the welded wire mesh layers the ductility of the specimen can be made marginally more than the control specimen. 


\subsection{Cracks}

The cracks developed in the specimen are shown in figure below. It can be observed that the cracks in the control specimen are mainly flexural and the specimen with double layer welded wire mesh also mainly flexural. But when we use single layer of mesh the cracks developed are both flexural and as well as shear failure.

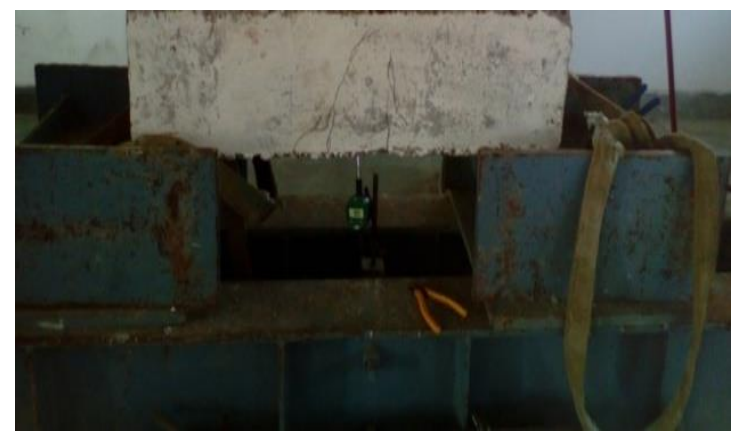

Figure 14 Crack 4. Conclusion

The conclusion of this paper, are presented by investigating varying mesh layers and proportion of silica fume of the control beam specimen. The inferences are

- The flexural strength and ultimate load of the beam increases nominally and remains unaffected compared to that of the control specimen.

- The maximum deflection increases considerably with adding one layer of control specimen.

- When the shear stirrups are completely replaced with two layers of welded wire mesh with $4 \%$ of silica fume replacement instead of cement, then the behavior of the beam is better than the conventional beam also the other combination of beams.

- When the percentage of silica fume is increased, then the strength values decrease considerably when compare with SP 4.

- Since there is reduction in cost, the use of welded wire mesh is found to be, suitable alternative to conventional shear stirrups.

\section{CONCLUSION}

This project is to examine the flexural behavior and crack pattern of RC beam. Totally five variations of beam were caste and number of mesh layers with percentage of silica fume are varied in each specimen. It is obtained that the beam with continuous welded wire mesh and longitudinal bar given the maximum load carrying capacity and it is found that there is improvement in strength characteristics while using mesh layer and silica fume when compared with control specimen.

\section{REFERENCES}

[1] C. Shermi, R.N. Dubey (2018). In-plane behaviour of unreinforced masonry panel strengthened with welded wire mesh and mortar. Construction and Building Materials 178 (2018) 195-203, Elsevier.

[2] Gul Ahmed Jokhio, Fatehi Mansoor Saad et.al. (2018). Uniaxial compression and tensile splitting tests on adobe with embedded steel wire reinforcement. Construction and Building Materials 176 (2018) 383-393, Elsevier.

[3] Fernando Pelisse, Alexandre Vieira et al. (2018). Efficient self-compacting concrete with low cement consumption. Journal of Cleaner Production 175 (2018) 324e332, Elsevier. 
Experimental Investigation on Flexural Behaviour of Flowable RC Beam Using Welded Wire Mesh as Shear Reinforcement

[4] Ibrahim G. Shaaban, Yousry B. Shaheen et al. (2018). Flexural characteristics of lightweight ferrocement beams with various types of core materials and mesh reinforcement. Construction and Building Materials 171 (2018) 802-816, Elsevier.

[5] Taha A. El-Sayed, Abeer M. Erfan (2018). Improving shear strength of beams using ferrocement composite. Construction and Building Materials 172 (2018) 608-617, Elsevier.

[6] Jun Li, Chengqing Wu et al (2017). Experimental and numerical study on steel wire mesh reinforced concrete slab under contact explosion. Materials and Design 116 (2017) 77-91, Elsevier. 